\title{
On the Interface Principles for Intonational Focus
}

\author{
Mats Rooth \\ IMS, Universität Stuttgart
}

\section{The indirect/anaphoric theory}

I will take for granted the the approach to the grammar of focus presented in Rooth (1992). There I propose logical forms for focus involving a focus feature $\mathrm{F}$ interpreted by a focus interpretation operator $\sim$, as exemplified in the trees bclow.

(1)

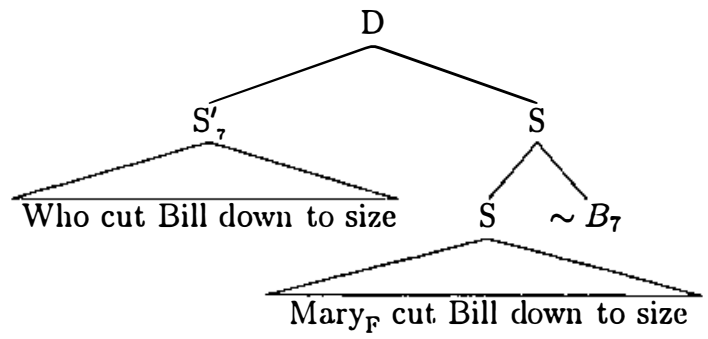

(2)

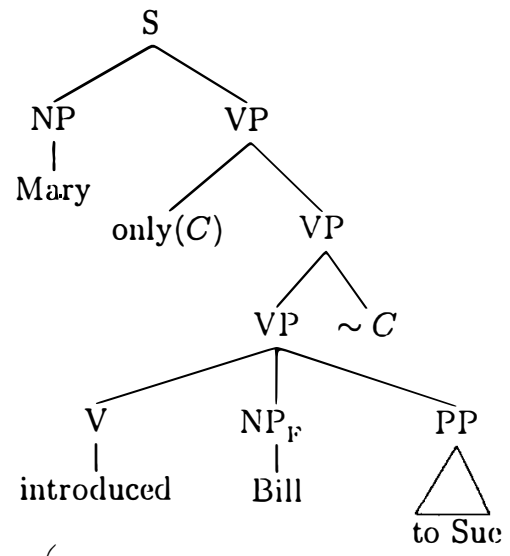


(3)

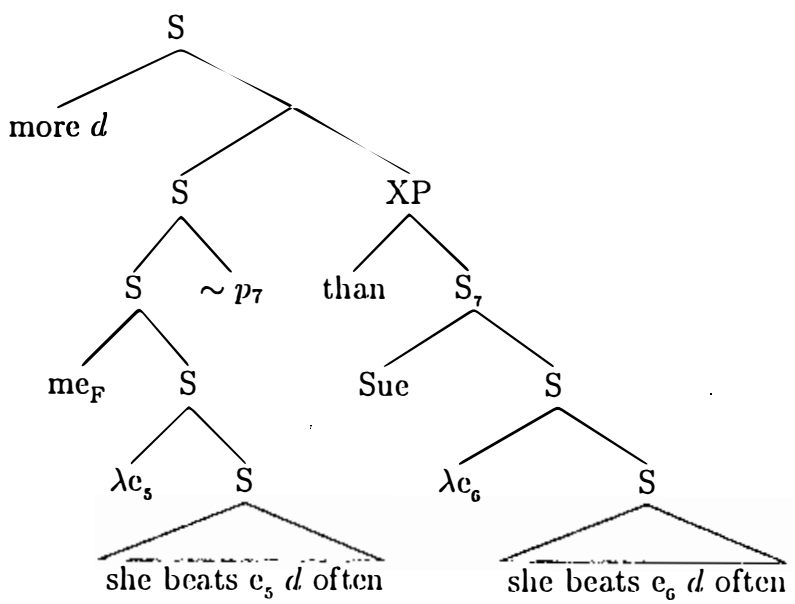

The goal of this theory is to provide a uniform and explanatory account of focus effects such as question-inswer congruence (exemplificed in (1)), focusing adverbs (5), and focus effects in bare remnant comparatives (6-8).

(4) Q: Who cut Bill down to sizc?

Appropriate answer: Mary cut Bill down to size.

Inappropriatte answer: Mary cut Bill ${ }_{F}$ down to size.

(5) Scenario: John introduced Bill and Tom to Sue, and there were no other introductions.

a. John only introduced [Bill] $]_{p}$ to Sue. (false)

b. John only introduced Bill to $[\text { Suc }]_{\mathrm{F}}$. (truce)

(6) a. she beats [nec] ]: nore of teen than Sue (= than she beat.s Suc)

b. $[\text { she }]_{\text {F }}$ beats nne more often than Sue (= than Sur beat.s mer)

(7) a. she likes [me $]_{1:}$ well conough, but not Sue (= she doces not. like Sue)

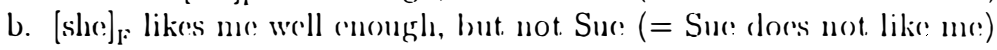

(8) a. she visited [me $]_{1}$ before Sue (= before slae visitecl Sue)

b. [she $]_{F}$ visited une before Sure (= before Sue visited mere)

The theory maintains that the role of focus is to (croke a contrastiun proporsition or set of propositions. In the treess alovere, these contrasting objectes anre

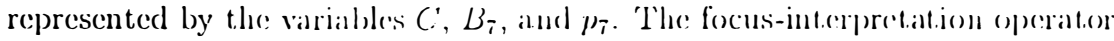
$\sim$ places a focus-determined constraint on the varialse: the propositions are obtainable by making sulstitutions in the position of the focused phatase. In the rule below, $\llbracket \phi \rrbracket^{\prime \prime}$ is an ordinary semantic value, which in the case of a sentence is a proposition. 【ל $\rrbracket^{7}$ is a set of propositions, roughly those propositions

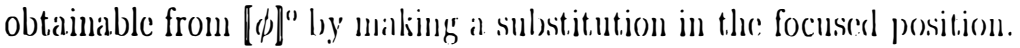


(9) a. Set case: Where $\phi$ is a syntactic phrase and $C$ is a syntactically covert semantic variable, $\phi \sim C$ introduces the presupposition that. $C$ is a subset of $\left[\phi \rrbracket^{\mathbb{f}}\right.$ containing $\llbracket \phi \rrbracket^{\circ}$ and at least one other element.

b. Individual case: $\phi \sim \psi$ introduces the presupposition that $\psi$ is an element of $\llbracket \phi \rrbracket^{\mathfrak{f}}$ distinct from $\llbracket \phi \rrbracket^{\circ}$.

Thus the architecture of the grammar of focus is as follows. The operator $\sim$ introduces a variable into an LF representation which is constrained by the semantics (9). The variable is linked up with something else in the representation by means of indexing. In tree.(1), the coindexed phrase is the question; in tree (2), the coindexed item is a covert domain-of-cquantification variable for only, and in trec (3) the coindexed phrase is the than-clause in the comparative. Linking up the focus-constrained variable with a particular antecedent is viewed as a matter of anaphora. The advantage of this approach is that focus-sensitivity follows from the independently motivated scmantics and/or pragmatics of a discourse configuration, syntactic configuration, or lexical item; it is not necessary to stipulate focus-sensitivity in a rule referring directly to a focus feature or focus-determined semantic information. Let us call this the indirect-anaphoric theory of association with focus; for cliscussion, see von Fintel (1994) and Krifka. (1996), in addition to Rooth (1992).

\section{Optionality of association with focus}

The analysis reviewed above predicts that focus-sensitive effects should be optional, for two reasons. First, adjoining a focus-interpretation operator at a particular place in LF is an optional process. Second, once a focus-constrained variable is present, the theory does not fix the antecedent for that variable.

The following example was cited in Rooth (1992) as applarent evidence for optionality.

(10) Pcople who [grow $]_{F}$ rice generally only [catt $]_{F}$ rice.

Judging by the meaning, there should be a focus on rice associated with only. But phonetically, it seems that no focus on rice is marked. Rather, there is a focus on cat motivatecel by contrast. with grow. The assumption that that, there indeed is no focus on rice leads to the following LF, guoted from Rooth (1992). 
(11)

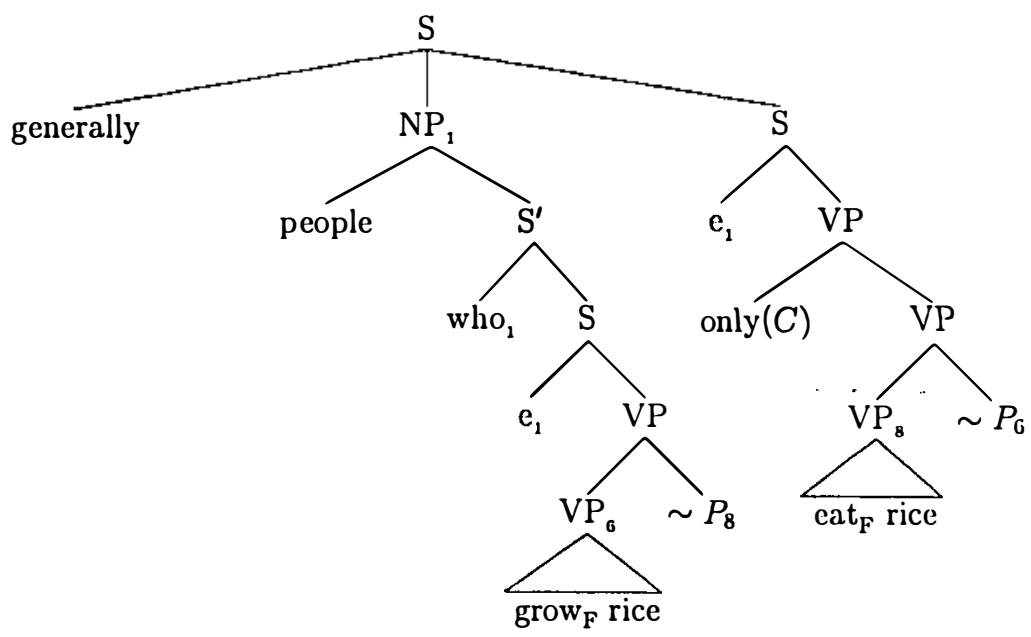

In this representation, there is no focus-determined constraint on the variable $C$ contributing the domain of quantification for only. As a consequence, this domain of quantification would just have to be worked out based on pragmatic reasoning, something which hardly seems objectionable.

A variety of similar examples have been given in the literature:

(12)a. Eva only gave xerox copies to the [GR $\Lambda D U \Lambda T E]_{F}$ students.

No, PETR only gave xerox copies to the GRADU $\operatorname{TTE}_{\mathrm{SOF}}$ sturlents.

(Partee (1991))

b. We only introduced Marilyn to [JoIIN $]_{F}$ Kennedy.

(i.e. not to Bobby and Edward Kennedy)

We also only introduced $[\text { Sue }]_{F}$ to $[\text { JoIIN }]_{\text {SoF }}$ Kemnedy.

(Rooth (1993))

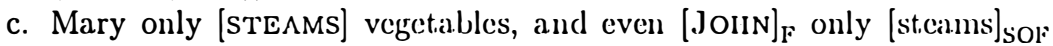
vegetables.

Krifka (1996)

In each example, the final bracketed phrase is the locus of a sccond occurrence focus. To explain the notation, the $F$ subscript marks a position where it is uncontroversial that, there is a focus, whatever this amounts to in a particular theory. The sof subscript marks a position where, from the point of vicw of certain theories of focus-sensitive effects, one would expect there to be a focus feature, but where the usual phonetics of focus is missing. The interest, of such examples lies in the fact that the indirect-anaphoric theory (or as explained presently, onc version of it) predicts that there should be such optionality effects. In contrast, a varicty of other approaches to focus and association with focus make the prediction that there is a focus feature inside the argument of any focus-sensitive opcrator such as only. One theory with this consequence is the structured meaning approach to the scmantics of focus von Stecliow (8589). 
It is possible to pose the theoretical question within the Rooth (1992) theory of the grammar of focus. In what in that paper was called the intermediate theory (as opposed to the strong theory), only stipulates in its lexical entry that focus is interpreted on the argument. That is, the lexical entry for only specifies the following local phrase-structural configuration, where XP is the argument.

(13) $[\operatorname{only}(\mathrm{C})[\mathrm{XP} \sim C]]$

Since it turns out that the presence of a $\sim$ operator entails the presence of a focus in XP, this lexical entry stipulates the presence of a focus in the argument of the focusing adverb.

I will call structured meanings and the intermediate theory association by rule theories of association with focus, because they stipulate in rules of grammar-directly or indirectly - that there is a focus feature inside the argument of any occurrence of only. The argument from second occurrence phenomena against association by rule theories runs as follows.

i. Association by rule theories of focus sensitive constructions require a focus feature (and the corresponding semantics) within the argument of each focus-sensitive operator.

ii. The phonological reflex of the focus feature is pitch accent.

iii. There is no pitch accent in SoF positions.

iv. Therefore there is no focus feature in SOF positions.

v. So SOF configurations involve a focus-sensitive operator without a focus feature in their argument.

vi. Since (i) is in conflict with (v), association-by-rulc theories can not represent sof examples, and are therefore refuted.

vii. The indirect-anaphoric theory is supported, because it decouples the semantics of descriptively focus-sensitive constructions from the focus feature.

In this article, I will show that contrary to this line of reasoning, second occurrence phenomena are not evidence for the indirect-anaphoric theory of association with focus. In fact, properly understood, they appear to be evidence against it. The first part of the argument has to do with phonetic datia indicating that rather than being phonetically unrealized, second occurrence foci are realized in a special way. This is not a novel observation, since it was made in Rooth (1992) and in a different way in von Fintel (1994). But for the purposes of my argument, it is important to get a more detailed conception of the phonetics and phonology of second occurrence focus. ${ }^{1}$ 


\section{The phonetics of second occurrence focus}

To my ear it is clear that at least many instances of sof, though reduced in some sense, are still prosodically prominent. For instance, I think that in natural renditions of $(12 \mathrm{a}),(12 \mathrm{~b})$, and (12c) the sof phrase is quite clearly prominent. I investigated the nature of this prominence in an informal way, by making recordings of several discourses. The recordings were of my own voice, and were made under uncontrolled circumstances; I merely tried to make the discourses sound natural.

The points I would like to establish are (i) that second occurrence focus has realization distinct from that of ordinary focus, involving prominence but no pitch movement, and (ii) this special realization is not triggered simply by one focus being under the scope of another; rather, a discoursc antecedent is required.

Below are examples involving a single focus.

(14)a. Eva only [named $]_{F}$ Manny

b. Eva only named [Manny $]_{F}$

The choice of words is motivated by the desire to avoid unvoiced segments, which disrupt pitch tracks. To contextualize the examples, one can imagine that Eva and her friend Sue have a bunch of cats. Eva got to pick Mamny's name; the others were named by Sue. The women also split uj) other (luties to be performed when one adopts a kitten. In Manny's case, Eva attcended only to the naming, leaving everything clse to Sue. Thus Eva only NAMED Manny-she didn't take him to the vet or teach him to use the litter box. And she only named MANNY-the other cats were named by Sue.

In my renditions of these sentences, the foci correlate with very prominent pitch movements. The reader will have to take this for granted, since I don't. have space to present the instrumental clata.

Next I consider examples which, although they involve two foci, as out-of-

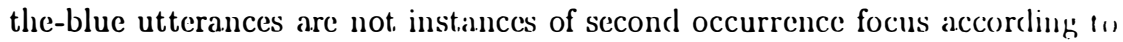
my criteria.

(15)a. Even Eva only [named] $]_{\mathrm{F}}$ Manny today.

b. Even Eva only named [Mamny $]_{F}$ today.

(16)a. I only want Eval to only [name $]_{F}$ Manny today.

b. I only want Evia to only name [Manny $]_{F}$ todlay.

To trigger the pronunciation under discussion, the context should not involw. a discussion of naming cats. Imagine that (15) opens a new subject of conversation and is preceded by "Guess what." Example (16) is less plansible ats an out-of-the-blue utterance. But, it can be contextualized as an answer to t.lir. question "what do you want people to do today?". ${ }^{2}$

The point I want to malic about thesc cxamples is that, although thery" involve two foci, the second, semantically subordinate focus is still realizol 
by a pitch movement. Figures 1 and 2 present wave forms, spectrograms, and pitch tracks for (16a) and (16b) respectively. The pitch tracks at the bottom of the figures illustrate a correlation between pitch movements and the location of the second focus; in figure 1, there is a pitch maximum in the region of the boundary between the vowel /A/ and the nasal / $\mathrm{m} /$ in named, while pitch is flat or irregular in the region of Manny. ${ }^{3}$ Converscly in figure 2, therc is a pitch maximum near the transition between the vowel /a/ and the nasal /n/ in Manny, while pitch is flat in the region of named.

In the theory of focus realization of Selkirk (1984) and much subsequent work, the phonological correlate of focus is a pitch accent aligned with a syllable within the focused phrase. According to such accounts, (16a) has a pitch accent aligned with the syllable nucleus / $\mathrm{Am} /$ in named, and no pitch accent aligned with the syllable nucleus /an/ in Manny. In (16b), the situation is reversed: there is a pitch accent on Manny, but none on named. This representation appears to be compatible with the pitch contours in the figures.

Now let us turn to genuine second occurrence focus. In each variant below, the second occurrence focus is conditioned by a context sentence with parallel structure.

(17)a. A: Paul only [named $]_{F}$ Manny today.

B: So what. Even $[\text { Eva }]_{F}$ only [named $]_{\text {SoF }}$ Manny today.

b. A: Paul only named $[\text { Manny }]_{F}$ today.

B: So what. Even $[\text { Eva }]_{F}$ only named $[\text { Manny }]_{\text {SoF }}$ todlay.

(18)a. A: Do you want Sue to to only [name $]_{F}$ Manny today?

B: No. I only want Eva to only [name $]_{F}$ Manny today.

b. A: Do you want Sue to only name [Manny $]_{F}$ today?

B: No. I only want Eva $a_{F}$ to only name [Manny $]_{F}$ today.

Pitch contours for the second sentences in (18a) and (18b) are given in figures 3 and 4 . Comparing figure 3 to figure 1 and figure 4 to figure 2, the. striking difference is that a pitch movement marking focus on named or Mannn!y is absent in the second occurrence examples. In figures 3 and 4 , pitch is flat in the second occurrence position. This supports the view taken in the literature that second occurrence focus is linguistically different from ordiniry focus. Clearly, in these utterances there is a gross phonetic difference between ordinary focus and second occurrence focus. This must be due to some representational difference, such as the absence of a pitch accent in second occurrence positions.

Listening to these utterances, though, a difference is evident between the final sentence in (18a), with a second occurrence focus on named, and the final sentence in (18b), with a second occurrence focus on Mann.ny. To the car and brain, the focus associated with only is clcarly marked. It is implausible thatl. this is attributable to differences in pitch, given the flat pitch contours in the: region of the second occurrence foci. How then is the second occurrence focus marked in these examples? Examination of the waveform and spectrogrimus 


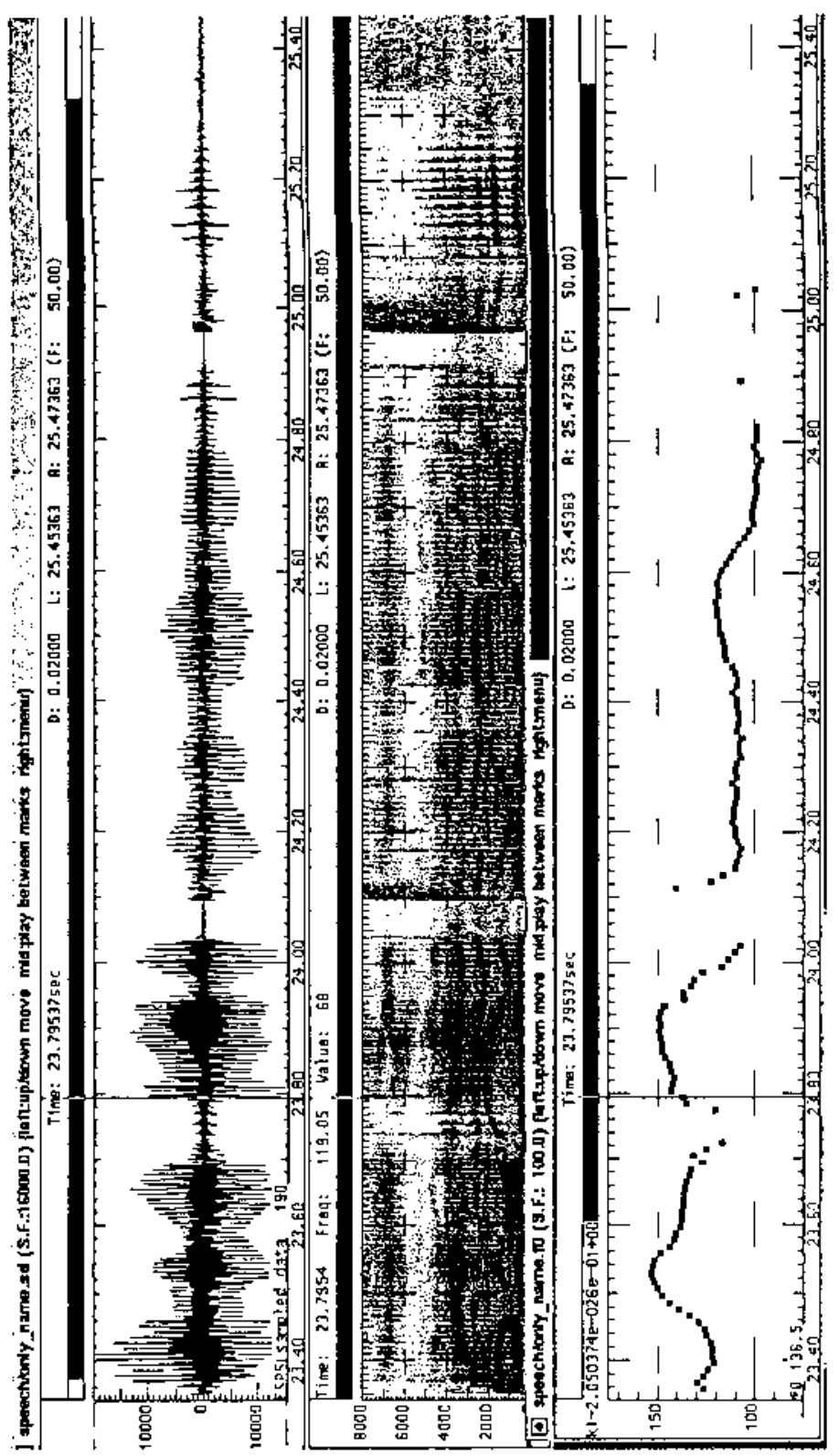

Figure 1: I only want $\operatorname{Ev\Lambda (23.9)~to~only~NAME(21.5)~Mamny(21.7)~toclay~}$ 


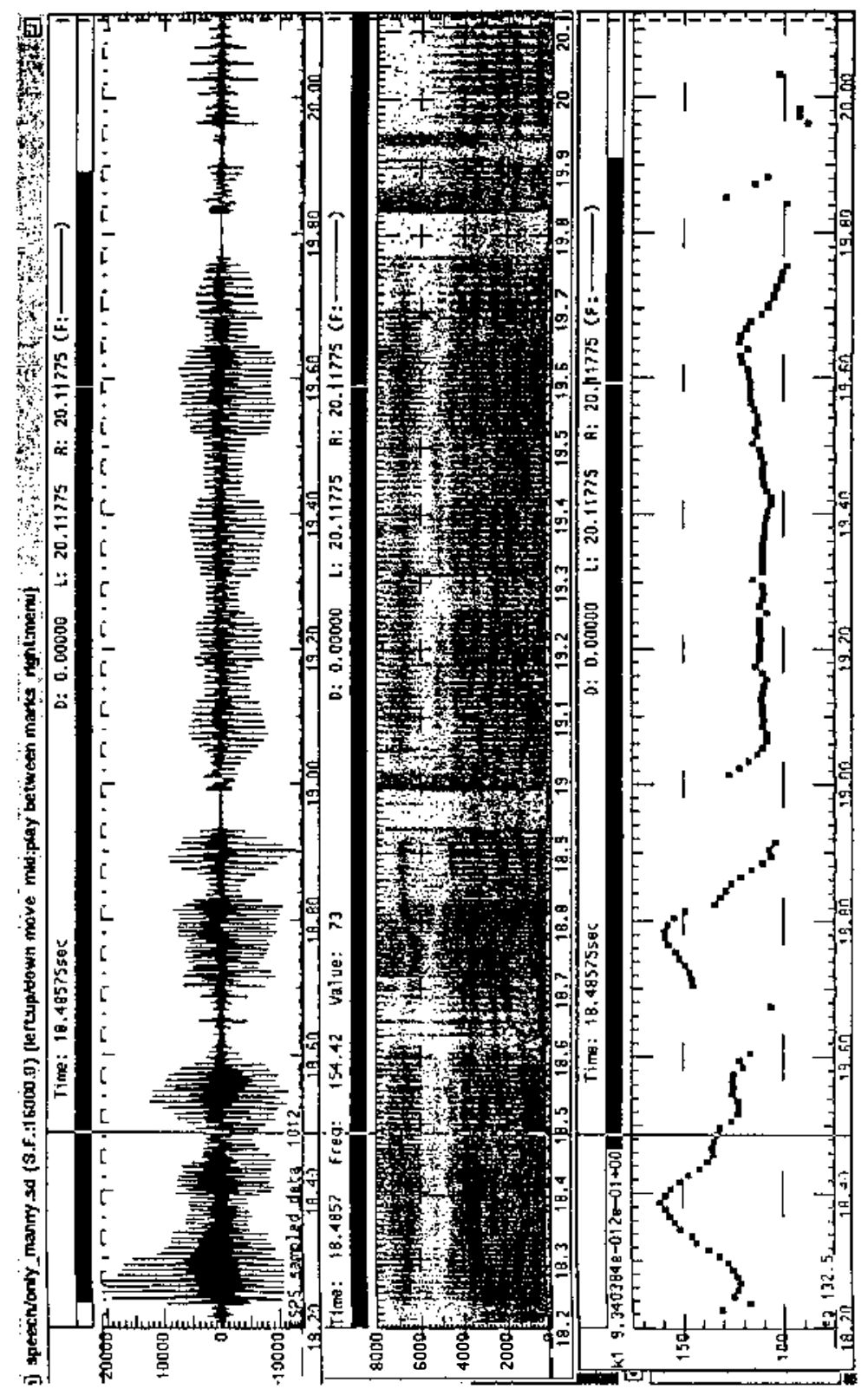

Figure 2: I only want $\operatorname{Ev\Lambda (18.8)~to~only~name(19.4)~} M \wedge N N Y(19.6)$ todiay 


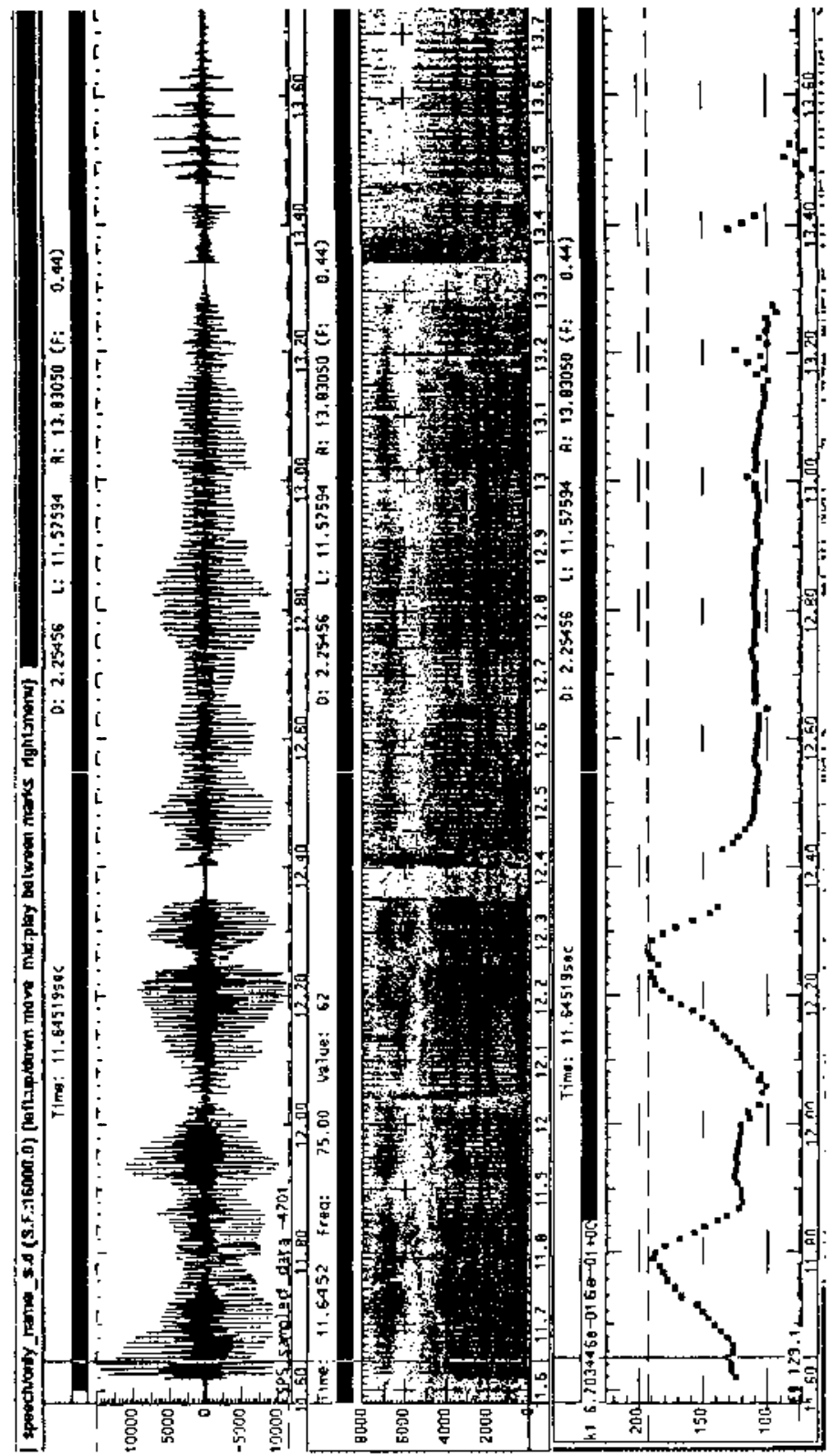

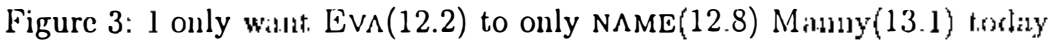




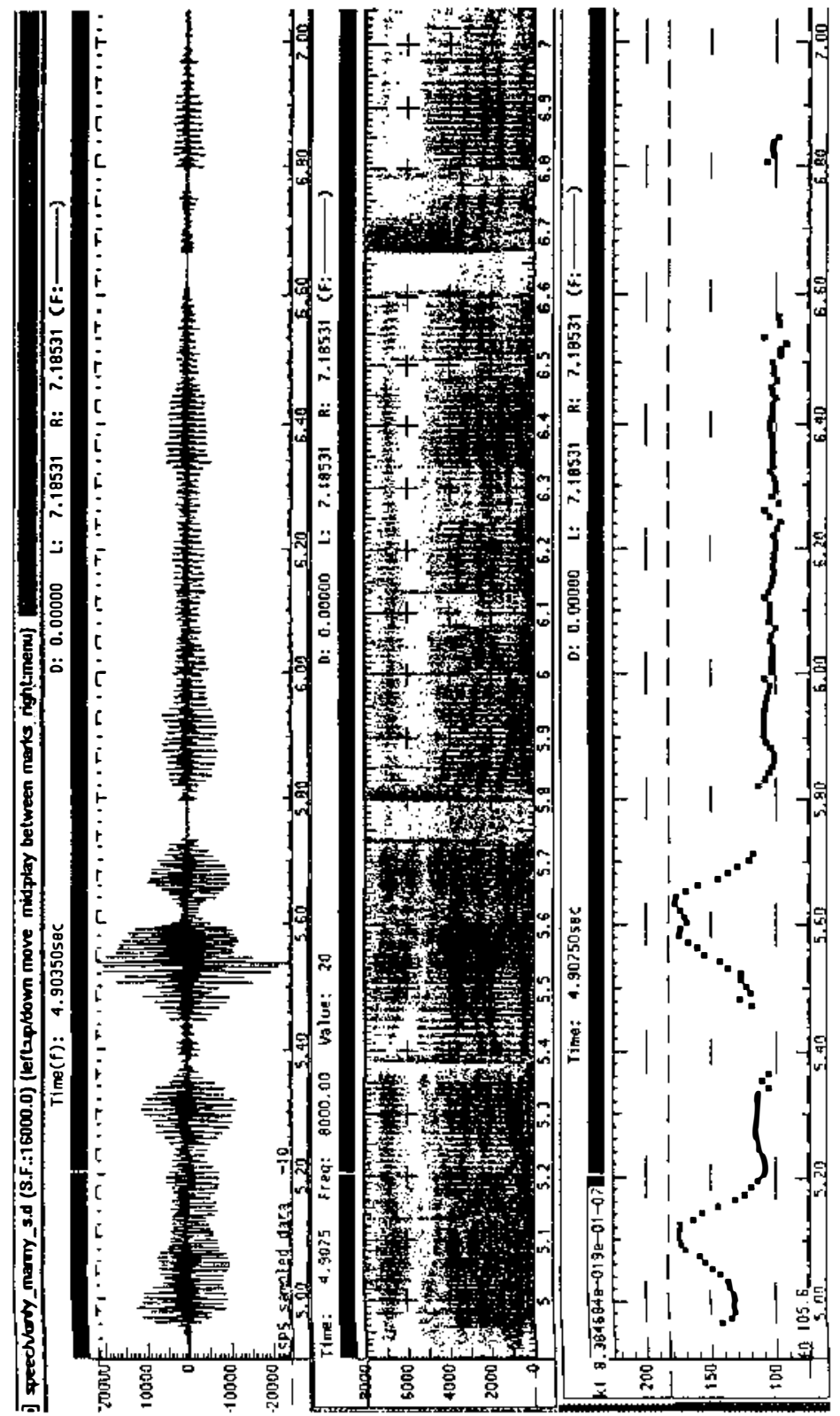

Figure 4: I only want. EvA(5.55) to only name(6.2) MANNy(0.4) todlay 
in figures 3 and 4 suggest that the intuited difference has a basis in physical reality. First, in figure 3, the the amplitude of the vowel nucleus /Am/ in named is greater than the amplitude of the nucleus /an/ in Manny. 4 In figure 4 this relation is reversed: the amplitude is greater in the vowcl nuclcus in Manny than in the vowel nucleus in named. Second, consider vowcl durations. In the spectrogram, the vowel in each case shows up as a dark block between two nasals. In figure 3, the vowel /A/ in the sof phrase named is longer than the vowel /a/ Manny. In figure 4, this relation is reversed: the vowel /a/ in the SOF phrase Manny is longer than the vowel /A/ in the nonfocused named. Thus in these utterances second occurrence focus corrclates with greater duration and intensity, though not with pitch movement.

These observations are hypotheses which have to be confirmed, quantified, and modified on the bases of systematic experimentation. But given the aclditional fact that in intuition it is clear that the locus of second occurrence focus is detectable, it scems safe to conclude that sof correlates with signal parameters other than pitch, perhaps including duration and amplitude. To draw conclusions regarding the grammar of focus, it is not necessary to know what parameters thesc are.

\section{Weak pronouns}

There is a pattern of clatia which is closely allied with the so phenomenon, due to Susanne Tunstall and cliscussed in von Fintel (1994) and Krifka (1996). I will present a variant of von Fintel's argument.

The pronouns him, her, and them can occur as full forms, and in the phonologically cliticized forms which I will writc as $i m, c r$, and $c m$. In a cliticized rendition of the sentence below, the realization of the verl phrase like her is similar except. in the first segment to the single word liliker.

(19) Do you likcr?

Tunstall observed that. second occurrence focus on a pronoun blocks cliticizaltion.

(20) Mary's boyfriend only' likes IIER.

\#Even her BOss only likser.

The example can only be rendered with a full pronoum, which I asisume to have: second occurrence phonology:

(21) Mary's boyfriend only' likes IIER.

Even her BOSs only likes her.

Apparently some spealiers find the example bad, however it is prononnced; these are the intuitions which von Fintel reports. The importint point is that. the cliticized rendition (2(0) is not possible in this context.

I interpret these datia, which I find quite clear, in the following way. Thes pronoun her carries a focus feature, explaining the intuited somantics. In (21), 
the focus feature is realized by second occurrence phonology, i.e. prominence in the absence of pitch accent. Such prominence is incompatible with cliticization, explaining the fact the the cliticized version (20) is perceived as ungrammtical, or rather as not conveying the meaning which is appropriate in context.

Thus the weak pronoun data lead to exactly the same conclusions as a consideration of the phonetics of other so phrases. It's just that pronouns provide a very sensitive probe for the phonological prominence which correlates with focus. For this reason, Tunstall's paradigm is easier to work with than other so data.

Von Fintel draws the same conclusion from the pronoun data as that reached here.

\section{Bridging and the SOF configuration}

The principal fact that a theory of second occurrence focus has to account for is a correlation betwecn semantic/pragmatic interpretation and phonological/phonetic realization. SOF has a phonology superficially distinct from the phonology of ordinary focus, and it is apparently licensed by a special complex discourse and/or syntactic configuration. What cxactly is this configuration? In the examples discussed above and in the rest of the literature on the subject, two patterns suggest themselves. First, in all of the examples, there is another competing focus in the same sentence with wider scope. In terms of LFs involving the focus interpretation operator, we have the following pattern:

$$
\left[\ldots F \ldots\left[[\ldots \mathrm{SOF} \ldots] \sim \Gamma_{2}\right] \ldots\right] \sim \Gamma_{1}
$$

The first focus is the primary focus, which is interpreted by the operator $\sim \Gamma_{1}$. Within the scope of this operator, we have another focus interpretation operator $\Gamma_{2}$ which interprets the focus which surfaces with so phonology.

Second, in all of the examples, there is a sentence in context which has a focus in a position parallel to the position of the so focus, and which contributes an antecedent for the varialsle $\Gamma_{1}$.

Both of these points are illustrated in the representation below, which involves a discourse node dominating two sentences. 
(22)

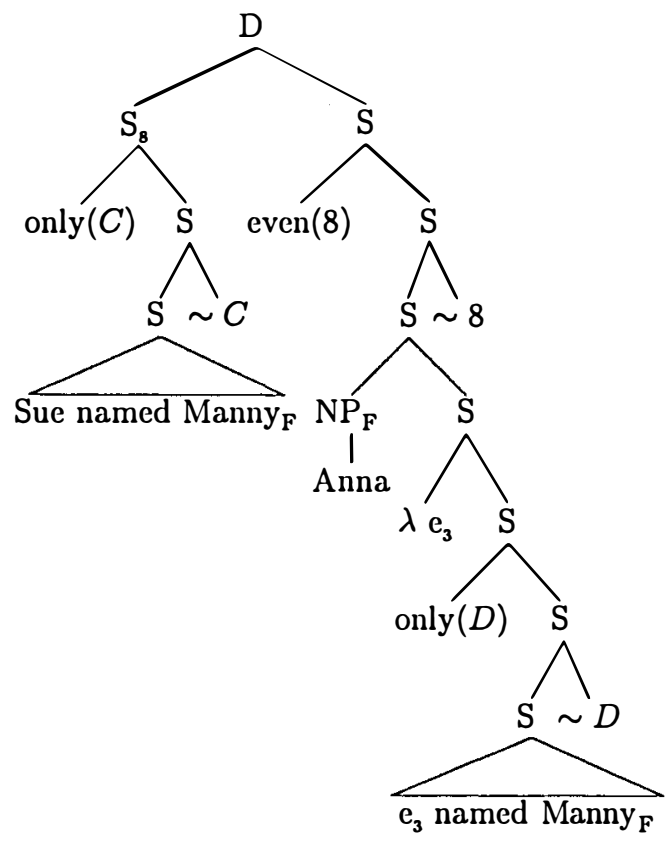

In the second sentence, the so focus on Manny is interpreted by $\sim D$, which constrains the domain of quantification for only. This configuration is cmbedded under the scope of a second focus interpretation $\sim 8$, the antecedent for which is the first clause. 5 This first clause contains a focus configuration parallel to the more embedded focus configuration in the second cla.usc.

This configuration is complex, and it is implausible that any principle of grammar would refer to all of it at once. In fact, the part involving the focus in the first sentence can be shown to be irrelevant. As pointed out in Lakoff (1971), contrastive focus and/or anaphoric reduction can be mediated by entailment. ${ }^{6}$ His examples are the following:

(23)a. John told Mary she was ugly, and the shé insulted hím.

b. John called Mary \{a. whore, a Republican, a. virgin, a lexicalist.\}, and then shé insulted him.

In the last variant of (23b), the bridging entailment is that calling someone a. lexicalist (combined with unstated premises) entails insulting them.

In Rooth (1992b) I cliscussed the following example:

(24) First somcone told Suc about the planned budget cuts, and then [JiLL heard about them]

In this case there is a simple entailment from someone telling Suc about the budget cuts to Sue hearing about them.

The relevance of the bridging phenomenon to the present discussion is that 
it shows that discourse licensing of focus does not require that the licensing clause be syntactically parallel to the clause hosting the reduced material. This observation extends to the focus structure of the antecedent in second occurrence configurations, as shown by an example which combines so focus with implicational bridging:

(25) The provost and the dean aren't taking any candidates other than Susan and Harold seriously.

Even [the chairman $]_{F}$ is only considering [younger $]_{S O F}$ candidatess.

The phrase younger has the phonetics of sof. The background assumption which licenses focus on [the chairman] in the second sentence is that Susan and Harold are among the younger candidates.

This datum shows that a parallel focus in the antecedent is incidentala second occurrence focus need not be a repeated focus. This is important, because it eliminates analyses involving copying phonological features of the antecedent. In the examples discussed earlier, one might propose that. prosody in the so region is inherited from the prosody of the parallel material in the antecedent. This might be the basis for an analysis where, contrary to the trend of the argument made in this paper, there is no focus feature in the so position. But this strategy is defeated by example (25), where there is no parallel focus structure in the antecedent.

The same point applies to a strategy of copying the scmantics of the antecedent. Krifka (1996) proposes an ingenious analysis of sof in which the so focus is included in a reduction anaphor which simply picks up its interpretition from the antecedent. This has the consequence that the region surrounding the so focus, including the focusing adverb which appears to associate. with the so focus, is not interpreted by the normal process of compositional interpretation. Kriflia suggests that this vitiates the argument from so phenomena against association-by-rule theorics of association with focus. If the focusing adverb which appears to associate with the so focus is not compositionally interpreted, it need not have a focus in its argument, and we no longer have the problematic situation of a focusing adverb without a focus within its argument. This point is not directly relevant to the present discussion, since it assumes that so focus is not phonologically realized, a position which I have argued against. But for the record, (25) shows that the analysis of the second occurrence phenomenon can not involve copying from the antecedent the semantics of the clausc hosting the so focus, since in this example this scmanticics is not not uniquely determined by the antecedent.

I draw quite general conclusions from the bridging example: the so phenomenon has nothing to do with grammatical parallelism with the antecedent, such as parallelism in focus structure. The sole aspect of the antecedent which is relevant to the so phenomenon is the proposition it denotes. Finally and most significantly, there is a focus feature in the so position which has the grammar and interpretation of ordinary focus features-the same compositional semantics and mode of interaction with focusing operators. Nothing 
else can explain why (25) has the specific interpretation that it has: the understood contrast between considering younger candidates and considering older candidates has no overt source other than a focus on younger.

At this point, we have a hypothesis about the LF of second occurrence focus:

$$
\left[\ldots \mathrm{F} \ldots\left[[\ldots \mathrm{SOF} \ldots] \sim \Gamma_{2}\right] \ldots\right] \sim \Gamma_{1}
$$

To capture the distinction involving discourse antecedents discussed in section 3 , we would want to require in addition that $\Gamma_{1}$ have a discourse antecedent. But the grammatical structure of that antecedent is not relevant.

\section{Turning the argument around}

Here again is the indirect/anaphoric theory of focus effects, illustrated for only:

i. $\sim \Gamma_{k}$ is freely adjoined in LF.

ii. The lexical entry for only stipulates a free domain of quantification variable, with type of a set of propositions. Nothing in this lexical entry refers to focus features, focus semantic values, etc.

iii. The variable constrained by focus interpretation is linked up with the domain of quantification for only by anaphora.

It follows from these assumptions that focus can be uscfully used to restrict the: domain of quantification for only. But it does not follow that every occurrence of only has an associated focus in its structural scope.

At this point, we have defeated the argument from second occurrence focus for the indirect/anaphoric theory. We have show that there is an $\mathrm{F}$ feature in sof positions, though it has a special realization. Let us go further. Tha' indirect theory seems to predicts that under suitable circumstances-when the domain of quantification for only is given by the discourse context-it should not be necessary to use focus in the argument to give information about the domain of quantification. This suggests that in the example below, it should not be necessary to place focus on the italicized pronoun in order to supply it domain of quantification for the second occurrence of only. The reason is that the understood domain of quantification is already present in the immediatc. discourse context: it is the same as the domain of quantification for the first. occurrence of only.

(26) A: You didn't do your job as a host. You only introduced Bill to Suc. B: *It's beC $\Lambda$ USE I only introduced him to her that they harl such in good time. So I did do my job as a host.

Using Tunstall's pronoun test, we can show that this prediction is not borne out. I find the following realization of B's response quite bad:

(27) B: \#It's becsuSE I only introducedim toer that they had such an goos time. So I did do my job as a host. 
Yet on the indirect/anaphoric theory, we could assume the following representation, where the domain of quantification for only in the second sentence is picked up from the first sentence.

$$
\begin{aligned}
& \ldots \text { only }(\Gamma)\left[\left[\text { you introduced }[\text { Bill }]_{F} \text { to Sue }\right] \sim \Gamma\right] \\
& \text { It's beCAUSE only }(\Gamma)[\text { I introduced him to her }] \text { that ... }
\end{aligned}
$$

Here there is no focus interpretation on the argument of only. But only has the right domain of quantification, picked up from the context. Thus the indirect-anaphoric theory incorrectly predicts (27) is appropriate in the indlicated context.

The same argument can be made relative to examples which do not involve second occurrence focus. Below, there is an indirect question which would on Hamblin (1973)'s analysis of the semantics of questions make available the set of propositions of the form 'John's sister likes $x$ '. But apparently this is not. sufficient to supply the domain of quantification for only:

(29) I don't much care who John's sister likes, though I doubt that she only likesim.

In the indirect/anaphoric theory, one could assume the following representiation, without any focus interpretation on the argument of only.

(30) I don't much care [who docs John's sister likes], though I doubt that. only $(8)$ [she likes him]

So, as before, the indirect-anaphoric theory incorrectly predicts that. (29), with a cliticized pronoun, should be good.

What I have just gone through is an argument against the strong version of the indirect-anaphoric theory of association with focus. It is a somewhat weak argument though, because it takes the view that, since the above LFs have the: right meaning, they should necessarily be acceptable. But there is a puzzlinf phenomenon regarding presuppositional operators which has a character rat her similar to these data. In certain cases, it is practically obligatory to use focus and/or presuppositional particles to give overt representation to parallelisun in denoted propositions. There is something quite odd about the first eximulle below. ${ }^{7}$

(31)a. First she punched me. Then she punched me.

b. First she punched me. Then she punched me again.

Contemporary dynamic theorics of presupposition do not give an account of the near obligatoriness in certain cases of presuppositional particles-ratther, such particles are gratuitously included in sentences, only to have the presuppositions they introduce filtered out. So, such near-obligatoriness shomlal be considered an uncxplained property of presuppositions. In the perspective of Rooth (1992), focus is treated as presuppositional. Therefore it might be possible to view the above data as part of the larger problem of obligiatoriness of presuppositional opcrators. If so, they do not count against the: 
indirect/anaphoric theory.

The option just outlined strikes me as tortuous, though. If all instances of only come with a focus interpretation operator, there is no objection to writing this into the lexical entry of only. The phenomenon of incorporation in lexical entries of semantic elements which can also be introduced compositionally is familiar in lexical semantics. For instance, Jackendoff (1990) proposes that when the verb put occurs with a locative rather than a path prepositional phrase, the path component of meaning is introduced by the lexical semantic representation of the verb.

(32)a. John put the book on the table. (locative)

b. John put the book into the bag. (path)

\section{Further issues}

The phenomenon I have been looking at interacts with a lot of other questions, and without examining them, I can not make a very definitive proposal. However, I do have a rough idea of an analysis, which I now outline. The logical form of focus is as in Rooth (1992): phrases bear F features, and the scope of an $\mathrm{F}$ feature is marked by a corresponding focus interpretation operator, which has a variable as a covert argument. This argument is identified with some other index or discourse referent in the representation. Some focus-sensitive operators-such as only-lexically incorporate a focus interpretation opcrator, so that their lexical entry stipulates association with focus.

The phonological interpretation of the $F$ feature is not pitch accent, but metrical prominence: within the scope of a focus interpretation operator, the corresponding $F$ is the most metrically prominent element. Depending on other factors, this prominent clement might or might not surface with a pitch accent. In particular, in the configuration repeated below, the first focus but not the sccond one surfaces with a pitch accent.

$$
\left[\ldots F \ldots\left[[\ldots F \ldots] \sim \Gamma_{2}\right] \ldots\right] \sim \Gamma_{1}
$$

At present, we are not in a position to say why this is so; it might be the result of the mapping between syntax and phonology, the presence of pitch accents being sensitive to certain semantically significant factors such as discourse anaploricity. Or it might be the result of a phonological rule which deletes a pitch accent, subject to a structural description involving inferior metrical prominence.

I now turn to specific questions which are relevant to filling in the above sketch, and which in part suggest that there is substantial cmpiricial territory to be explored before an analysis can be formulated. 


\section{Left-right order}

In the examples I looked at above, the so focus follows the primary focus. This seems to be significant. In the examples below, the focus on Manny follows the primary focus on Anna, and is realized without pitch accent. (In the first version, I find the absence of pitch accent on Manny obligatory. In the second version, a rendition with pitch accent seems possible, thought I prefer a version without one.)

(34) John likes only Manny.

a. Even Anna $_{F}$ likes only Manny .

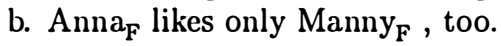

Now we switch the order of the phrases [only Manny] and [even Anna], continuing to pay attention to the contextually appropriate reading where the even quantification and its associated focus have wicle scope. ${ }^{8}$

(35) Only Manny likes John.

a. Only Manny likes even Anna $_{F}$.

b. Only Manny likes Anna , too.

Here my intuition is that the focus on Manny is obligatorily an accented focus. Thus in this paradigm, the semantically less prominent (i.e. narrower scope) focus surfaces without a pitch accent only if it follows the more prominent focus. This is suggestive of the doctrine of nuclear accents, according to which a final accent has a distinguished status as most prominent. Suppose that (i) there is a constraint that the final accented position is the metrically most prominent position, and that (ii) semantic scope of focus is reflected in metrical prominence. It follows that a focus with inferior scope which follows the focus with superior scope can not be realized with a pitch accent. (Alan Prince suggested something like this in the discussion after my talk.) This idea is intriguing, though if falls short of explaining why accent on Manny should be obligatory in (35), or why it should be marginally possible in the second option of (34). ${ }^{9}$

There is another relevant configuration for the left/right assymmetry, where the focusing adverbs are both to the same side of the foci:

(36) We only [introduced $]_{F}$ Marilyn to John.

$\mathrm{We}$ also $_{1}$ only $_{2}$ introduced $_{\mathrm{F} 2}$ Marilyn to Bobby $_{\mathrm{F} 1}$.

Here the nested scope relationship of the foci is in a sense more clear, because the association-with-focus relations are nested. I feel that as before, the first focus is realized with an accent, though I would like to makc a recording to be sure of this. If we reverse the order of primary and secondary foci, the secondary focus is realized with so phonology.

(37) We only introduced Marilyn to $\mathrm{John}_{\mathrm{F}}$ Kennedy.

We also only $_{2}$ introduced $\mathrm{Suc}_{\mathrm{F} 1}$ to John $\mathrm{SOF}_{1}$ Kennedy. 


\section{Discourse givenness}

As I have already stated, he pattern (33) does not in itself capture the contextual givenness of material containing the so focus. But as was argued in section 3, this seems to be relevant. Here is another example, which again should be thought of as an out-of-the-blue utterance.

(38) Even the mayor's closest supporters are saying that only his opponents have any chance of winning.

Although even semantically has maximal scope, the focus associated with only is realized with a pitch accent. Evidently, the difference from so cxamples is that here there is no context sentence which supplies an antecedent for reduction of material containing the focus associated with only. This shows that relative scope of focus is not the only relevant parameter for so phonology; discourse anaphoricity is also relevant.

If I pronounce (38) with a so realization of the focus on opponents, I get a strong suggestion of a context where an antecedent is explicitly available. It is delicate, though, to say what 'explicitly' amounts to. We have already seen that so focus can be implicationally bridged. One can also set up scenarios without any linguistic antecedent at all. Consider the following context for Krifka's steaming example. I am staying at your house for a few clays. After a third observation of your cooking technique, I can say without any previous discussion of the matter:

(39) I ALSO only $[\text { stcam }]_{\text {SOF }}$ my vegetables.

This conveys something in the direction of my taking it to follow from what is going on in your kitchen that you systematically cook your vegretiables by steaming, and that I assume you will agree with this conclusion.

Focusing adverbs differ as to whether they require relatively overt antecedents: as we saw with (38), everu does not require an overt antecent, while also does require one. Thus the following is no good without a relatively overt antecedent (also is to be understood as associated with the subject): ${ }^{10}$

(40) The mayor's closest supporters are also saying that only his opponents have any chance of wimning.

What is one to make of these points at a theoretical level? Instcad of saying anything substantial about the characterization of relatively overt licensers, I will limit myself to describing a suitable interface. Suppose that among the variables used as arguments of the focus interpretation operator, there is a distinguished subset used for 'overt' licensers. In terms of the representiation above, the second focus below would be realized with second occurrence phonology if $\Gamma_{1}$ is an overt-intecedent variable.

$$
\left[\ldots F \ldots\left[[\ldots F \ldots] \sim \Gamma_{2}\right] \ldots\right] \sim \Gamma_{1}
$$


It is seems desirable to decompose this into one part having to do with a relation between relative prominence and the scope of foci, and another part having to do with pitch accent realization. For the first part, we can say that in the configuration

$$
[\ldots \mathrm{F} . . .] \sim \Gamma_{1}
$$

where $\Gamma_{1}$ is an overt-antecedent variable, $F$ is metrically more morc prominent than anything else in the scope of $\sim \Gamma_{1}$. The sccond part is the nuclearaccent principle, according to which no pitch accents are realized after the most prominent syllable in an intonational phrase.

\section{Phonological characterization}

The discussion in this section has been based on the hypothesis that there is no pitch accent in SOF positions. There is one alternative which has to be eliminated, that so foci are marked by $\mathrm{L}^{*}$ pitch accents. For the main argument made in this article, this would make no difference; but this issuc is nevertheless an interesting one. According to Pierrehumbert and Hirschberg (1990), $L^{*}$ accents can convey that " $\mathrm{H}$ [the hearer] should already be aware of what $\mathrm{S}$ [the speaker] is saying". They give the following example:

(41) A: Let's order the Chateaubriand for two.

B: I don't eat beef

$\mathrm{L}^{*} \quad \mathrm{~L}^{*} \mathrm{~L} \mathrm{H} \%$

The impact here is an insulting suggestion that A should already have becu aware of B's dietary preferences. This might be thought of as a pragmatic effect based on a semantics of contextual givenness, establishing a possible connection with second occurrence data.

An argument against an $\mathrm{L}^{*}$ analysis which occurs to $\mathrm{me}$ is to look at, so focus in questions:

(42) John only steams ${ }_{F}$ his vegetables.

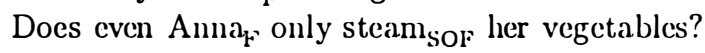

My impression (without having looked at the matter in detail) is that, there is that pitch on steam is quite high. To the extent that the specific pattern is inconsistent with a low accent, and consistent with the interpolated pitch movement produced by HH\$ boundary tones marking the yes/no cuestion, this would yield an argument for the absence of a pitch accent in the so position, based on phonetic realizations rules for accent in the tone-sequence mordel.

\section{The rice example}

One loose end in this discussion is the example repeated below.

(43) People who $[\text { grow }]_{F}$ rice generally only $[\text { cat }]_{F}$ rice. 
The intuition here is that there is no intuitively perceptible prominence on rice, thought at this point we have good reason to think that there is a focus feature in this position. Here I will repeat what I said in Rooth (1992): once we have shown that most foci-including many so foci-are phonctically and phonologically realized, cases like this do not count against association by rule theories. We analyze the example with a focus feature on rice. Since there is nothing else in the postnuclear area with which to compare any prominence on rice, it is easy to see why prominence on rice should not be perceptible.

\section{Conclusion}

My results are the following.

i. Second occurrence focus is phonologically and phonctically realized.

ii. Second occurrence foci bear a focus feature.

iii. The so phenomenon is not an argument for the strong version of the indirect-anaphoric theory.

iv. There is a weak argument (stated in section 6) for association-by-rulc theories, where lexical items are allowed to stipulate association with focus.

v. The phonological correlate of focus is metrical prominence rather than pitch accent.

vi. I stated a gencralization characterizing in terms of a.n LF configuration where focus is realized with so phonology.

The formalization referred to in the final point has the status of a gencralization stated in terms of suitable theoretical constructs. While it is appealingly abstract and removed from the immediate data, it falls short of being a theory, because it is not cmbedeled in a general account of the LF-phonology relation dealing with accent assignment, phrasing, and metrical prominence.

Point v. is really a hypothesis rather than a conclusion, since several alternatives are consistent with what has becn said here; so focus accents might be deleted by phonological rules, or not realized in plonetic implementantion. To flesh cither of these possibilities out, it would be necessary to identify a phonological context for the deletion or non-realization, and to relate the relevant, conditioning features to the LF of SOF.

One point which I systematically glossed over in presenting my LFs is the phenomenon of crosscatcegoriality. Focusing adverbs which are syntactically adjoined to NP were given clatusial scope in LF. Crosscategoriality of focusing adverbs is covered in Rooth (1985:ch 3), and in unpublished rescarch, I have worked out the semantics of a crosscategrorial focus interpretiation operator using similar methods. However, it unclear to me whether my implicit. 
promissory notes regarding the relative scope of foci can be paid off. The same reservation applies to expressing correlations between semantic scope and phonological prominence.

Looking towards a broader theory of the LF-phonology relation, it strikes me that the architecture in terms of which I argued, while useful for my purposes, is beginning to have a dilapidated look. An alternative which looks promising to me is the framework of Steedman (ms.), where it is possible to get much more of a grasp on semantically relevant aspects of accent and phrasing.

\section{Endnotes}

1. The following section appears in nearly identical form in Rooth (1996).

2. I find (15) a lot easier to deal with than (16); presumably the double negation adds complexity. And at this point, it requires some imagination to fit the discourses into the cat scenario; the word today was added on the end to make the focus non-final.

3. I use the informal notation for English vowcls of Chomsky and Halle (1968). The captions for the figures give approximate temporal locations of the prominent vowel nuclei of relevant words. The time labeling on the horizontal axis of the pitch tracks and other signals can be used to locate the relevint phonetic material.

4. In the figures, what is visible as a sequence of vertical bars in the waveform at the top of the figure is in fact a wave which is extremely compressed in the horizontal dimension. Where the bars are longer, the wave amplitude is greater.

5. Here I analyze the covert argument of even as being a single proposition, rather than a set of propositions as in Rooth (1985). With this semantic ty'je, the presupposition contributed by even is that the covert argument is true and is less likely than the overt argument.

6. Lakoff credits the observation t.o Georgia. Green and R.M.W. Dixon.

7. I belicve I owe this observation to Hans kamp).

8. But see the worrics below concerning whether this assumption about the scope of the focus is legitimate.

9. There are some interesting interactions with phrasing observalsle in (35). In (35a), a big intonational break between likes and evcn is preferred on the relevant reading. If I instead place a break between Mannny and likes, I don't get. the relevant reading. (35b) is more flexible: here I can get the relevant reading with the break in either place. This presumably has to do with the fact that. in (35a) the adverb cven is adjoined to the NP Mary, which as shown in Rooth 
(1985) attains its scope by quantifier scoping. It might be that the scoping mechanism here is type raising or string-vacuous cxtraposition, with an influence on phrasing. These observations suggest a complex interaction between the scope of focus, the realization of focus, and phrasing; Mark Steedman's work on focus and phrasing in a categorial framework is potentially relevant (Steedman ms.).

10. For association with subjects, it is actually not clear whether this difference has to do with the adverb rather than with the position of the adverb relative to the focus. The following example with even in auxiliary position does require a relatively overt liccnsing context, if there is no accent after even.

(i) The mayor's closest supporters are even saying that only his opponents have any chance of winning.

This ties in with the question whether subject-adjoined even has a presupposition as strong as what is maintained in many accounts. Consider the following example from Kempson (1975).

(ii) All the kids tried on something. Mary tried on a pair of trousers, Suc a long shawl. Even Max tried on a fancy tic.

As Kempson points out, the presupposition here is not that people other than Max tried on a fancy ties, but rather that people other than Max tried things on. This suggests that the semantics of subject-adjoined even involves, in the terminology of Rooth (1985), the focus scmantic values of both the subject and the VP, resulting in an optional association with a focus on or in the VP. The semantics maintained on standard accounts is obtained only when the VP has no focus.

\section{References}

Chomsky, N. and Halle, M. (1968). The Sound Pattern of English. Harper and Row, New York.

Hamblin, C. (1973). Questions in Montague English. Foundations of Lan.guagc, pages $41-53$.

Jackendoff, R. (1990). Scmantic Structures. MIT Press, Cambridge, Masssachusetts.

Kempson, R. (1975). Presupposition and the Delimitation of Scmantics. Cambridge University Press, Cambridge.

Krifka, M. (1996). Focus and/or context: a second look at second occurrence focus. In Kamp, H. and Partee, B., editors, Proccedinigs of thc Prague/Tainach works/lops. IMS, Universitity of Stuttgart. 
Lakoff, G. (1971). Presupposition and relative well-formedness. In Steinberg, D. and Jakobovits, L., editors, Semantics: an Interdisciplinary Reader. Cambridge University Press, Cambridge.

Partee, B. (1991). Topic, focus, and quantification. In SALT 1, pages 159-187.

Pierrehumbert, J. and Hirschberg, J. (1990). The meaning of intonational contours in the interpretation of discourse. In Cohen, P. R., Morgan, J., and Pollack, M. E., editors, Intentions in Communication, pages 271-311. MIT Press, Cambridge.

Rooth, M. (1985). Association with Focus. PhD thesis, University of Massachusetts, Amherst.

Rooth, M. (1992). A theory of focus interpretation. Natural Language Scmantics, pages 75-116.

Rooth, M. (1992b). Ellipsis redundancy and reduction redundancy. Paper presented at the March 1992 workshop on ellipsis, University of Stuttgart.

Rooth, M. (1993). A hybrid architecture for focus. Handout for talk given at the Amsterdam colloquium, $\mathrm{xx}$ pages.

Rooth, M. (1996). Comments on krifka's paper. In Kamp, H. and Partec, B., editors, Proceedings of Praguc/Tainach workshops. IMS, Universitity of Stuttgart.

Selkirk, L. (1984). Phonology and Syntax. MIT Press, Cambridge.

Steedman, M. (1996). Combinators and grammars. Unpublished book manuscript, University of Pcunsylvania.

von Fintel, K. (1994). Restrictions on quantificr domains. PhD thesis, University of Massacliusetts, Amlierst.

von Stechow, A. (1985/89). Focusing and backgrounding opcrators. Technical Report 6, Fachgruppe Sprachwisscnschaft, Universitä.t. Konstianz. 